\title{
Potencial de transdiferenciação neural das células-tronco mesenquimais da medula óssea de equino ${ }^{1}$
}

\author{
Leandro Maia ${ }^{2} *$, Fernanda C. Landim-Alvarenga ${ }^{3}$, Márjorie de Assis Golim \\ Mateus José Sudano ${ }^{3}$, Marilda O. Taffarel ${ }^{5}$, Bruna De Vita ${ }^{3}$, Natália Pereira P. Freitas ${ }^{2}$ \\ e Rogério M. Amorim²
}

\begin{abstract}
Maia L., Landim-Alvarenga F.C., Golim M.A., Sudano M.J., Taffarel M.O., De Vita B., Freitas N.P.P. \& Amorim R.M. 2012. [Potential of neural transdifferentiation of mesenchymal stem cells from equine bone marrow.] Potencial de transdiferenciação neural das células-tronco mesenquimais da medula óssea de equino. Pesquisa Veterinária Brasileira 32(5):444-452. Departamento de Clínica Veterinária, Faculdade de Medicina Veterinária e Zootecnia, Universidade Estadual Paulista, Distrito de Rubião Júnior s/n, Botucatu, SP 18618-970, Brazil.E-mail: leandromvet@hotmail.com

The first studies showing the potential of neural transdifferentiation of mesenchymal stem cells (MSCs) from bone marrow (BM) were conducted in camundogos and humans in the early 2000s. After this period, the number of research and publications with the same purpose increased, but with rare or scarce studies in horses. The aim of this study was to evaluate in vitro neuronal transdifferentiation potential of MSCs from equine BM using two protocols: P1 (forksolin and retinoic acid) and P2 (2-ßmecarptoetanol). After confirming the mesenchymal lineages, by positivity for the marker $\operatorname{CD} 90$ ( $\overline{\mathrm{X}}=97.94 \%)$, negative for the marker CD34 and positive response for osteogenic differentiation, MSCs were subjected to neural transdifferentiation (P1 and P2) for morphological analysis and expression of neural markers GFAP and $\beta 3$ tubulin by flow cytometry. The results revealed morphological changes in varying degrees between the tested protocols. In protocol 1, twenty four hours after incubation with the media of neural differentiation, a large proportion of cells $(>80 \%)$ had similar morphology to neural cells, characterized by retraction of cellular body and a large number of cytoplasmic extension (filopodia). However, comparatively, within the first 30 minutes after exposure to the antioxidant $\beta$-mercaptoethanol (P2) MSCs showed rapid morphological changes characterized mainly by retraction of cellular body and less cytoplasmic extension. It was also evidenced with the use of this protocol, lower cellular adhesion after exposure to media when compared to P1. Regarding the immunophenotyping analysis it was observed a higher $(\mathrm{P}<0.001)$ expression of the markers GFAP and $\beta 3$ tubulin at the end of P2 compared to P1. The ability of MSCs to generate cell types related to neural lineage is complex and multifactorial, depending not only of inducing agents, but also the environment in which these cells will be cultivated. Thus a greater number of studies are necessary to better understand the process of neural transdifferentiation of MSCs from equine.
\end{abstract}

INDEX TERMS: Horse, neural differentiation, adult stem cells, neural markers.

\footnotetext{
${ }^{1}$ Recebido em 15 de outubro de 2011.

Aceito para publicação em 23 de fevereiro de 2012.

${ }^{2}$ Departamento de Clínica Veterinária, Faculdade de Medicina Veterinária e Zootecnia (FMVZ), Universidade Estadual Paulista (Unesp), Distrito de Rubião Júnior s/n, Botucatu, SP 18618-970, Brasil. Bolsista FAPESP. *Autor para correspondência: leandromvet@hotmail.com
}

\footnotetext{
${ }^{3}$ Departamento de Reprodução Animal e Radiologia Veterinária, FMVZ-Unesp, Botucatu, SP.

${ }^{4}$ Hemocentro da Faculdade de Medicina, Universidade Estadual Paulista (Unesp), Botucatu, SP.

${ }^{5}$ Departamento de Cirurgia e Anestesiologia Veterinária, FMVZ-Unesp, Botucatu, SP.
} 
RESUMO-- Os primeiros estudos demonstrando o potencial de trandiferenciação neural das células-tronco mesenquimais (CTMs) provenientes da medula óssea (MO) foram conduzidos em camundogos e humanos no início da década de 2000. Após esse período, o número de pesquisas e publicações com o mesmo propósito tem aumentado, mas com raros ou escassos estudos na espécie equina. Nesse sentindo, o objetivo desse trabalho foi avaliar o potencial in vitro da transdiferenciação neural das CTMs provenientes da MO de equinos utilizando-se dois protocolos: P1 (forksolin e ácido retinóico) e P2 (2-ßmecarptoetanol). Após a confirmação das linhagens mesenquimais, pela positividade para o marcador CD90 ( $\bar{X}=97,94 \%)$, negatividade para o marcador CD34 e resposta positiva a diferenciação osteogênica, as CTMs foram submetidas a transdiferenciação neural (P1 e P2) para avaliação morfológica e expressão dos marcadores neurais GFAP e $\beta 3$ tubulina por citometria de fluxo. Os resultados revelaram mudanças morfológicas em graus variados entre os protocolos testados. No protocolo 1, vinte quatro horas após a incubação com o meio de diferenciação neural, grande proporção de células $(>80 \%)$ apresentaram morfologia semelhante a células neurais, caracterizadas por retração do corpo celular e grande número de projeções protoplasmáticas (filopodia). Por outro lado, de forma comparativa, já nos primeiros 30 minutos após a exposição ao antioxidante $\beta$-mercaptoetanol (P2) as CTMs apresentaram rápida mudança morfológica caracterizada principalmente por retração do corpo celular e menor número de projeções protoplasmáticas. Também ficou evidenciado com o uso deste protocolo, menor aderência das células após tempo de exposição ao meio de diferenciação, quando comparado ao P1. Com relação a análise imunofenotípica foi observado uma maior $(\mathrm{P}<0,001)$ expressão dos marcadores GFAP e $\beta 3$ tubulina ao término do P2 quando comparado ao P1. A habilidade das CTMs em gerar tipos celulares relacionados a linhagem neural é complexa e multifatorial, dependendo não só dos agentes indutores, mas também do ambiente no qual estas células são cultivadas. Desta forma um maior número de estudos é necessário para o melhor entendimento do processo de transdiferenciação neural a partir de CTMs de equinos.

TERMOS DE INDEXAÇÃO: Equino, diferenciação neural, células-tronco adultas, marcadores neurais.

\section{INTRODUÇÃO}

O interesse terapêutico e biológico nas células-tronco (CT) tem aumentando nos últimos anos, fato esse demonstrado pelo número crescente de pesquisas e publicações na área. De acordo com Frisbie \& Smith (2010), a grande atenção ou interesse no uso das CT está relacionado ao seu potencial de regeneração, o qual poderia ser atribuído aos efeitos parácrinos, migratórios, imunomoduladores, antiinflamatórios e antiapoptóticos já descritos na literatura (Brooke et al. 2007, Dahlgren 2009).

As CT podem ser definidas como células com grande capacidade de proliferação e auto-renovação, além da capacidade de responder a estímulos externos e dar origem a diferentes linhagens celulares mais especializadas. (Pereira 2008). De acordo com a origem tecidual as CT podem ser classificadas em células-tronco adultas e embrionárias. As CT embrionárias são aquelas derivadas da massa celular interna do blastócito, sendo totipotentes ou capazes de se transformar em qualquer tipo celular, e por sua vez em um organismo inteiro. As CT adultas incluem as células-tronco hematopoiéticas (CTH) e mesenquimais (CTMs), podendo ser isoladas de tecidos de origem mesordemal, tais como medula óssea, músculo, tendão, tecido adiposo (Dahlgren 2009), sangue periférico (Martinello et al. 2010), matriz do cordão umbilical (Hoynowski et al. 2007) e líquido amniótico (Lovati et al. 2011). As CTH são responsáveis pela produção da linhagem linfóide e mielóide e as CTMs são capazes de se diferenciar em tipos celulares de origem estromal, incluindo osso, músculo, cartilagem, tecido adiposo, ligamento e tendão (Dahlgren 2009). Adicionalmente, na opinião de Chen et al. (2008), em condições especiais essas células também possuem a capacidade de diferenciar em tecidos de origem ectodermal e endodermal, sendo facilmente isoladas e expandidas in vitro.

Os primeiros estudos demonstrando o potencial de transdiferenciação das CTMs em células neurais foram conduzidos por Woodbury et al. (2000) e Sanchez-Ramoz et al. (2000) que utilizaram células provenientes da medula óssea de humanos e roedores. Woodbury et al. (2000) utilizaram protocolos de transdiferenciação baseados em agentes químicos antioxidantes ( $\beta$-mercaptoetanol, butilato de hidroxianisole, dimetilsulfóxido), enquanto Sanchez-Ramoz et al. (2000) testaram protocolos com ácido retinóico e fatores neurotrópicos em células previamente tratadas com EGF. No primeiro estudo as células apresentaram rápida mudança morfológica, além da expressão de marcadores neurais. Atualmente, além da utilização dos agentes químicos, os protocolos baseiam-se na utilização de fatores de crescimento (Naghdi et al. 2009, Bae et al. 2011, Nourbakhsh et al. 2011), fatores neurotrópicos (Barzilai et al. 2008), líquido cefalorraquidiano autólogo (Ye et al. 2011) e fitoterapia (Hu et al. 2011). Particularmente na espécie equina, os estudos estão focados na demonstração da capacidade de diferenciação das CTMs-MO principalmente em tecidos de origem mesodermal, sendo inexistente ou escassa a avaliação do potencial de transdiferenciação neural. Nesse sentindo, o objetivo desse estudo foi avaliar o potencial de transdiferenciação neural das CTMs provenientes da medula óssea de equinos utilizando dois protocolos.

\section{MATERIAL E MÉTODOS}

\section{Animais}

Foram utilizadas oito amostras de medula óssea $(20 \mathrm{~mL} / \mathrm{amos}-$ tra) provenientes de quatro equinos mestiços hígidos, de ambos os sexos e com idade entre 4 a 12 anos, selecionados mediante a avaliação clínica e hematológica prévia. 0 protocolo experimental foi aprovado pelo comitê de ética e bem estar animal da Universidade Estadual Paulista Julio de Mesquita Filho, campus Botucatu. Todos os procedimentos foram realizados sob as diretrizes internacionais para o cuidado e uso de animais experimentais.

\section{Colheita da medula óssea}

A punção aspirativa da medula óssea (MO) foi realizada conforme a metodologia descrita por Barreira et al. (2008) com modificações. Para isso, os animais foram mantidos em estação, 
contidos em brete e sedados com 0,5 mg kg-1 xilazina (Sedomin ${ }^{\circledR}$, Köning, ARG). Em seguida, foi realizada a tricotomia de uma área de $5 \times 20 \mathrm{~cm}$ na região referente ao osso esterno de cada eqüino. Após a identificação da quinta esternebra foi realizado anti-sepsia e bloqueio anestésico local (Xylestesin ${ }^{\circledR} 2 \%$, Cristália, BRA). Uma vez bem fixa a agulha de punção modelo Komiyashiki ${ }^{\circledR}$ dentro do esterno, o mandril foi retirado e se procedeu a aspiração da medula óssea com auxílio de duas seringas de $20 \mathrm{~mL}$ contendo $2 \mathrm{~mL}$ de heparina a $5000 \mathrm{UI} / \mathrm{mL}\left(\mathrm{Hemofol}^{\circledR}\right.$, Cristália, BRA) e $2 \mathrm{~mL}$ de tampão Salina-Fosfato pH 7,2 (PBS ${ }^{\circledR}$ 1x, LGC Biotecnologia, BRA). Após a colheita, as amostras foram encaminhadas imediatamente ao laboratório e processadas.

\section{Isolamento e cultivo das células-tronco mesenquimais}

As amostras de MO foram previamente filtradas utilizando-se um equipo de transfusão (Biosani ${ }^{\circledR}, \mathrm{BRA}$ ), sendo em seguida procedida à primeira centrifugação (Centrifuga Hermle Z200A, GER) a $250 \mathrm{~g}$ por 10 minutos para descarte da gordura e plasma sobrenadante. Ao material remanescente adicionou-se meio DMEM baixa glicose (Invitrogen Gibco ${ }^{\circledR}$, USA) na proporção 1:1, sendo posteriormente acrescido o Ficoll- paque ${ }^{\mathrm{tm}}$ premium 1073 (GE Healthcare Life Sciences ${ }^{\circledR}$, SWE) lentamente(1:1) para separação da fração de células mononucleares a $350 \mathrm{~g}$ por 30 minutos. A fração mononuclear foi aspirada e lavada duas vezes em meio DMEM baixa glicose a $250 \mathrm{~g}$ por 10 minutos. Após a última lavagem o pelet de células mononucleares foi suspenso e cultivado em meio DMEM baixa glicose/F12 (1:1), 20\% soro fetal bovino, penicilina/estreptomicina (1\%) e anfotericina B $(1,2 \%)$ (Invitrogen Gibco $^{\circledR}$, USA) a $37,5^{\circ} \mathrm{C}$ em atmosfera úmida contendo $95 \%$ de ar e $5 \% \mathrm{CO}_{2} .0$ meio de manutenção foi trocado a cada 2 ou 3 dias até a confluência celular mínima de $80 \%$, onde se procedeu a tripsinização para caracterização e diferenciação dos subcultivos das CTMs.

\section{Análise na citometria de fluxo para os marcadores de super- fície celular}

A caracterização imunofenotípica das CTMs previamente a transdiferenciação neural foi realizada ao final do cultivo primário no citômetro FACSCalibur (Becton Dickinson and Company, USA), utilizando os anticorpos monoclonais mouse anti-rat CD90 (Caltag Laboratories, EUA) e mouse anti-human CD34 (Becton Dickinson and Company, USA) marcados com a sonda isoticiato de fluoresceína (FITC). Durante a análise foram contabilizados 10.000 eventos.

\section{Diferenciação osteogênica}

Após confluência de $80 \%$ em cultivo primário, as CTMS foram tripsinizadas com Triple express (Invitrogen Gibco ${ }^{\circledR}$, USA) e acondicionadas em placas de seis poços (Sarstedt ${ }^{\circledR}$, USA) com meio DMEM/F12 (1:1) acrescido de 20\% soro fetal bovino, antibiótico e antifúngico. Quarenta e oito horas após a incubação, o meio de manutenção foi removido e o meio de diferenciação osteogenico STEMPRO $^{\circledR}$ (Invitrogen Gibco ${ }^{\circledR}$, USA) foi acrescido ao subcultivo. 0 meio foi trocado a cada dois a três dias e, a confirmação da diferenciação osteogênica foi realizada mediante a demonstração da deposição de matriz de cálcio utilizando o método de coloração histológico com Alizarin red pH 4,2 (Sigma-Aldrich Corp, USA).

\section{Diferenciação neural}

A diferenciação neural foi conduzida testando-se dois protocolos de diferenciação para CTMs previamente caracterizadas. Os protocolos utilizados estão descritos abaixo:

Protocolo 1 (P1)- Meio basal para células-tronco neurais, acrescido de $5 \mathrm{mM}$ forksolin $(0,001 \%)$ e $500 \mu \mathrm{M}$ ácido retinóico $(0,002 \%)$ (Millipore Corporation $\left.{ }^{\circledR}, \mathrm{USA}\right)$ por 48 horas.
Protocolo 2 (P2)- Meio DMEM baixa glicose acrescido de $1 \mathrm{mM}$ 2-ßmercaptoetanol (0,007\%) (Sigma-Aldrich Corp ${ }^{\circledR}$, USA) (Woodebury et al. 2000, com modificações) por 18 horas.

Protocolo Controle - CTMs indiferenciadas não submetidas a tratamento e mantidas em meio DMEM baixa glicose/F12 na proporção de $1: 1$ acrescido de $20 \%$, soro fetal bovino, penicilina/ estreptomicina (1\%) e anfotericina B $(1,2 \%)$ (Invitrogen Gibco ${ }^{\circledR}$, USA).

As CTMs em primeira passagem e prévia caracterização foram mantidas em meio de manutenção do protocolo controle até a confluência celular de $80 \%$. Uma vez confluentes o meio de manutenção foi removido e os meios de diferenciação foram acrescidos. No protocolo 1, previamente a indução neural as células foram mantidas por 18 horas em meio basal para células-tronco neurais acrescido de $10 \mathrm{ng} / \mathrm{mL}$ fator de crescimento fibroblástico básico (Millipore Corporation $®$, USA). Após esse período foi adicionado ao meio basal o forksolin e ácido retinóico durante dois dias nas proporções discriminadas acima e com troca diária.

No protocolo 2 as células não foram submetidas a pré-diferenciação, conforme descrito por Woodebury et al. (2000), pois em estudos pilotos prévios verificamos que as células modificavam-se muito morfologicamente logo na primeira hora de tratamento, interferindo assim na avaliação do protocolo proposto.

Após o período de diferenciação as células foram preparadas para análise fenotípica utilizando-se os marcadores GFAP e $\beta 3$ tubulina. 0 processo de diferenciação, bem como de avaliação foram realizados em quadruplicatas para cada protocolo proposto.

\section{Citometria de fluxo para os marcadores neurais}

A analise fenotípica foi conduzida utilizando os anticorpo primários anti GFAP (Invitrogen Gibcoß, USA) e anti $\beta 3$ tubulina (Millipore Corporation $\AA$, USA) marcados com Alexa flúor 488. Para isso, as células provenientes de P1, P2 e CTMs indiferenciadas foram tripsinizadas, resuspendidas em PBS e acondicionadas em tubos de polipropileno (Becton Dickinson $\AA$ and Company, USA). Previamente a incubação com os marcadores, as células foram fixadas e permeabilizadas com o kit (Becton Dickinson $\AA$ and Company, USA) para facilitar a difusão dos anticorpos utilizados. Em seguida, os anticorpos foram adicionados e as células incubadas no escuro por uma hora para leitura no citômetro de fluxo FACS Calibur (Becton Dickinson $®$ and Company, USA).

\section{Analise estatística dos dados}

Para análise estatística, a variável dependente binomial (expressão das proteínas na citometria fluxo) dos diferentes protocolos foi analisada através do teste de regressão logística utilizando o PROC LOGISTIC do SAS (SAS, Inst. Inc., Cary, NC, USA). Quando o efeito de tratamento foi significativo utilizou-se o LSD com o comando LSMEANS PDIFF do PROC GLM do SAS. Fontes de variação no modelo, incluindo tratamento, foram consideradas como efeito fixo. Como efeito aleatório adotou-se os animais (tratamento). Os resultados estão apresentados como porcentagem. Foi adotado o nível de significância de $5 \%(\mathrm{P}<0,05)$.

\section{RESULTADOS}

As células provenientes da fração mononuclear da MO apresentaram aderência ao plástico entre 24 e 48 horas e morfologia fibroblastóide inicialmente com quatro dias de cultivo. No período compreendido de 15 a 22 dias ( $\bar{x}=22)$ de cultivo foi alcançada a confluência celular $\geq 80 \%$, sendo conduzida análise imunofenotípica para os marcadores CD90 e CD34 previamente a diferenciação neural. 
Fig.1. Análise imunofenotípica FACS das células-tronco mesenquimais de equino para os marcadores CD34 e CD 90. (A) Gráfico de distribuição e tamanho. (B) Controle. (C) Histograma do marcador CD90 expressoemmédia 97,94\%. (D) Histograma do marcador CD34 (negativo).
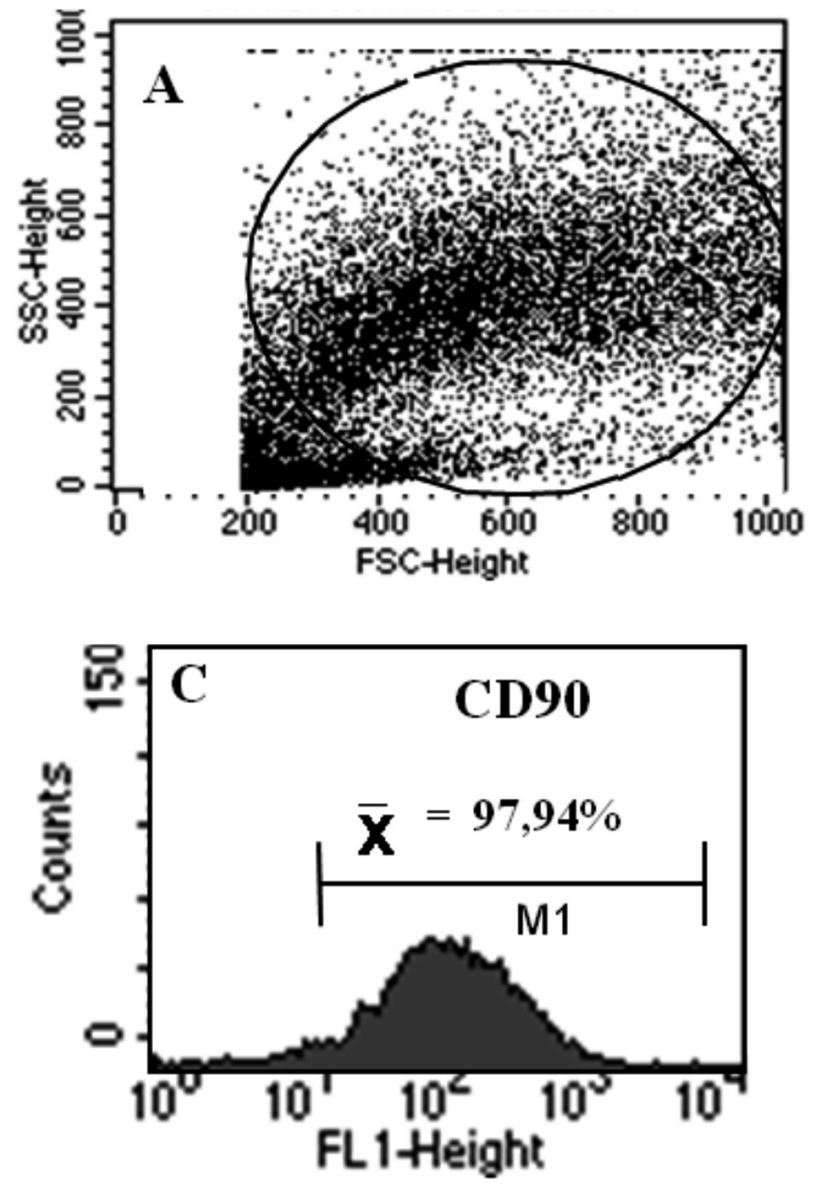
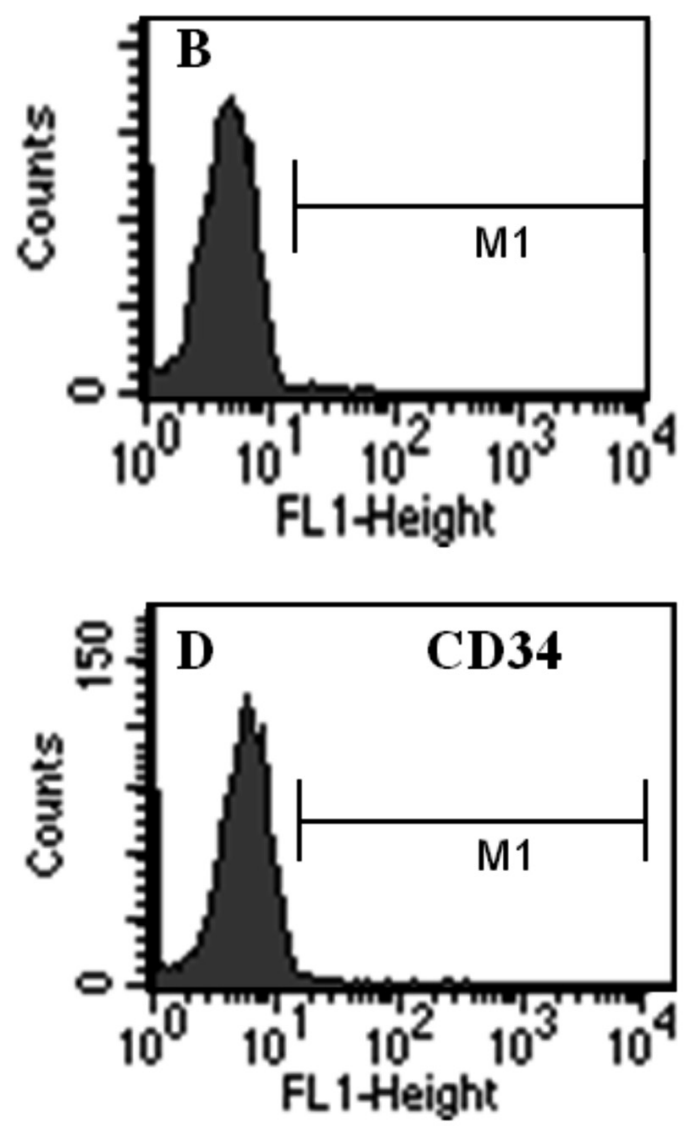

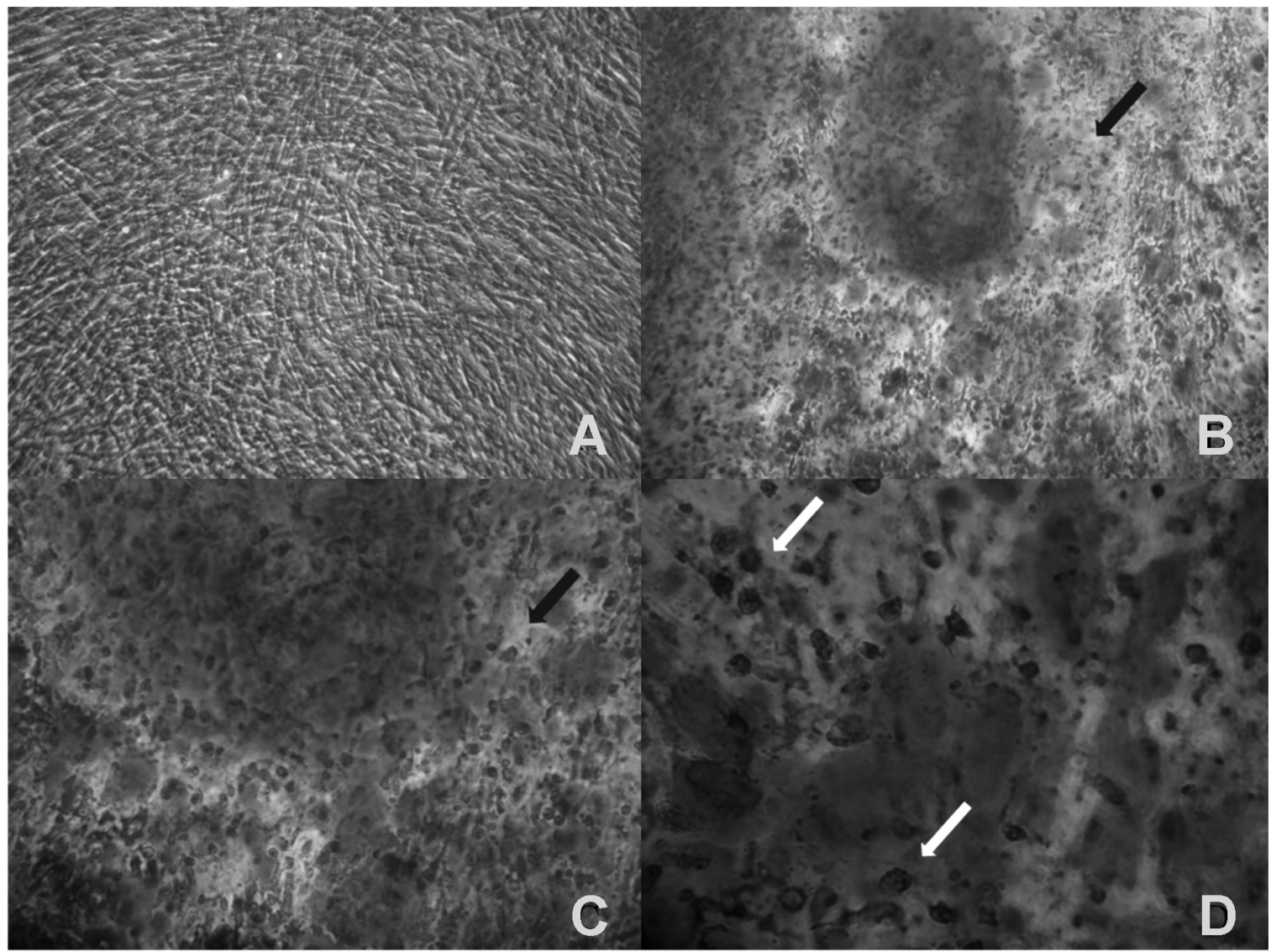

Fig.2. (A) CTMs indiferenciadas. Note a morfologia fibroblastóide característicadascélulas.0bj.10x.(B,C) Diferenciação osteogênica. Note adeposição de cálcio marcada com Alizarin red (seta azul). Obj.10x, 20x. (D) Note a mudança de morfologia fibroblastóide para poligonal das células após a diferenciação osteogênica (setas brancas). Obj.40x. 
A análise revelou elevada expressão do marcador CD90 $(\bar{X}=97,94 \%)$ e ausência de expressão para o marcador CD34, conforme demonstrado na Figura 1. Adicionalmente, o potencial de diferenciação das CTMs em outra linhagem mesenquimal foi confirmado pela diferenciação osteogênica 10 dias após a exposição ao meio de diferenciação. As CTMs inicialmente com morfologia fibroblastóide adquiriram morfologia predominantemente poligonal e depositaram grande quantidade de matriz extracelular de cálcio comprovada pela coloração positiva com Alizarim red (Fig.2).

A exposição das CTMs aos protocolos de diferenciação neural ocasionaram mudanças morfológicas em graus variados. No protocolo 1, após a exposição ao meio de pré-diferenciação, as CTMs demonstraram pequena retração celular. Vinte quatro horas após a incubação com o meio de diferenciação neural do protocolo 1, grande proporção (>80\%) de

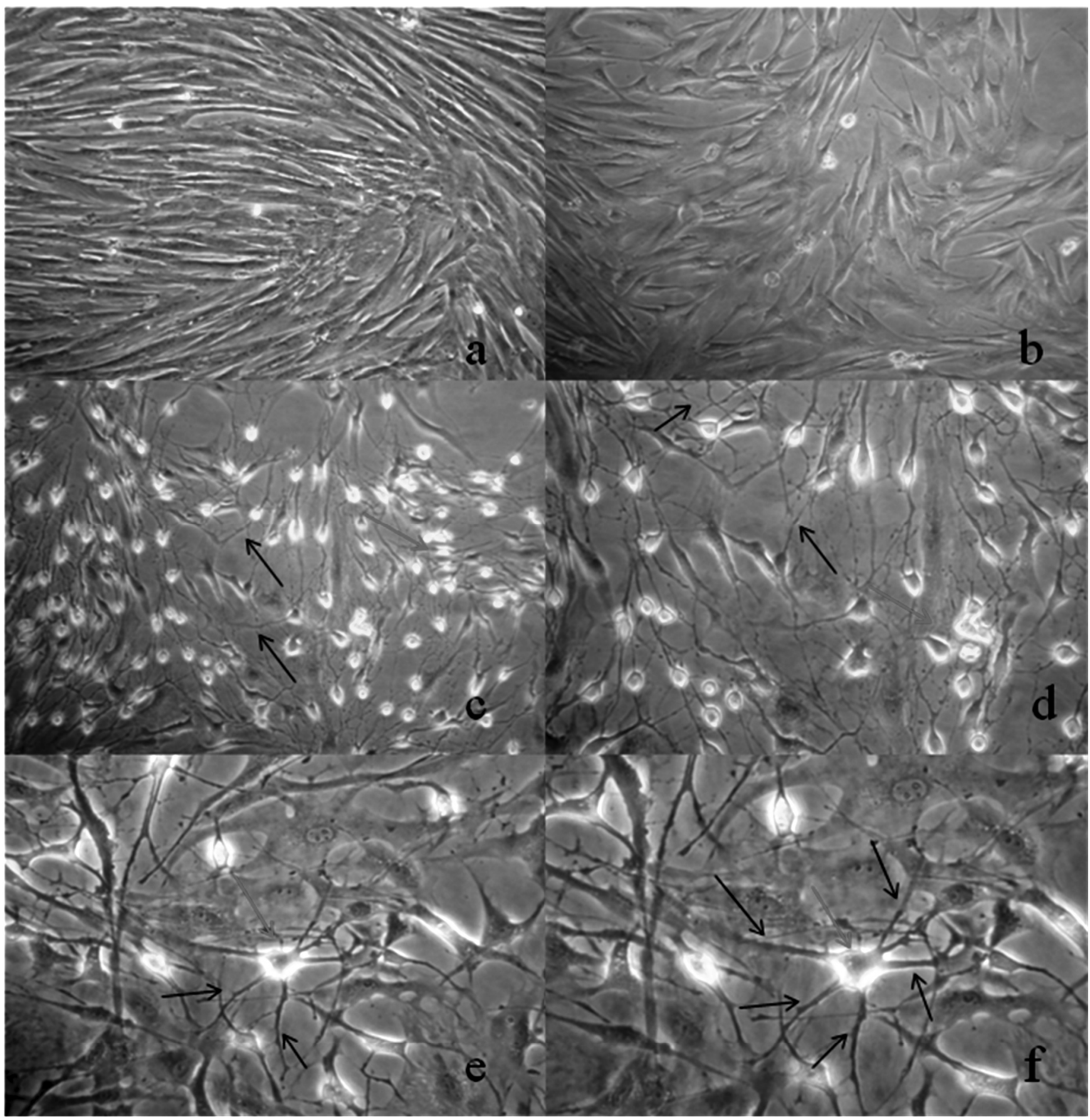

Fig.3. Diferenciação neural das CTMs com forksolin e acido retinoico (P1). (a) CTMs indiferenciadas demonstrando morfologia fibroblastóide. (b) Células após exposição ao meio de pré-diferenciação demonstrando discreta mudança morfológica. (c,d) Células apresentado retração do corpo celular (setas vermelhas) e presença de inúmeros prolongamentos citoplasmáticos (setas pretas) após 24 horas de exposição a P1. (e,f) Células apresentado retração do corpo celular (setas vermelhas) e presença de inúmeros prolongamentos citoplasmáticos (setas pretas) após 48 horas de exposição a P1. Obj.10x (c), 20x (a,b,d,e), 40x (f). 
células apresentaram morfologia semelhante a células neurais, caracterizadas por retração do corpo celular e grande número de projeções protoplasmáticas (filopodia) que se intensificaram ao término das 48 horas de exposição ao meio de diferenciação (Fig.3). Por outro lado, de forma comparativa, logo após a exposição ao antioxidante $\beta$-mercaptoetanol (P2), as CTMs apresentaram rápida mudança morfológica caracterizada principalmente por retração do corpo celu- lar e menor número de projeções protoplasmáticas (Fig.4). Também ficou evidenciada com o uso deste protocolo, menor aderência das células após tempo de exposição ao meio de diferenciação, quando comparado ao P1.

Com relação a análise fenotípica foi observada uma maior $(\mathrm{P}<0,001)$ expressão do GFAP em P2 $(95,2 \%)$ e no controle (91\%) em comparação ao P1 (76,8\%). Diferenças $(\mathrm{P}=0,3095)$ entre $\mathrm{P} 2$ e o controle não foram observadas. Já

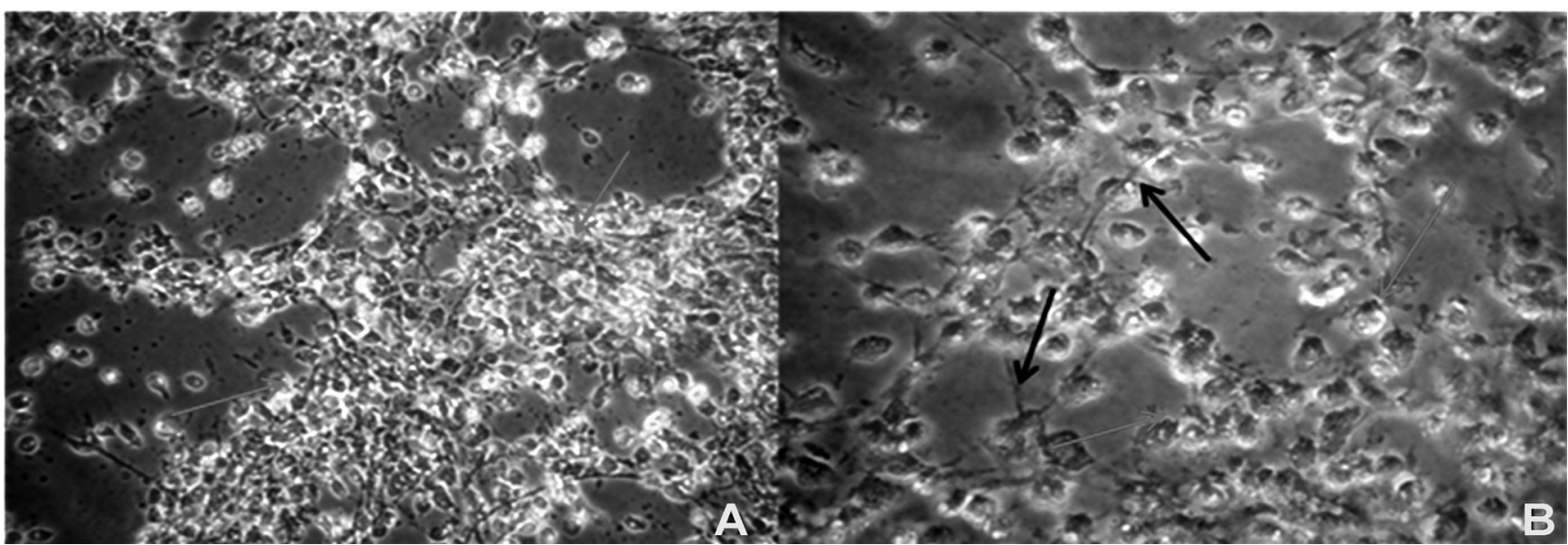

Fig.4. (A,B) Diferenciação neural das CTMs com 2-ßmercaptoetanol (P2). Células apresentado intensa retração do corpo celular (setas vermelhas) e presença de inúmeros prolongamentos citoplasmáticos (setas pretas) 0bj.10x (A), 20x (B).
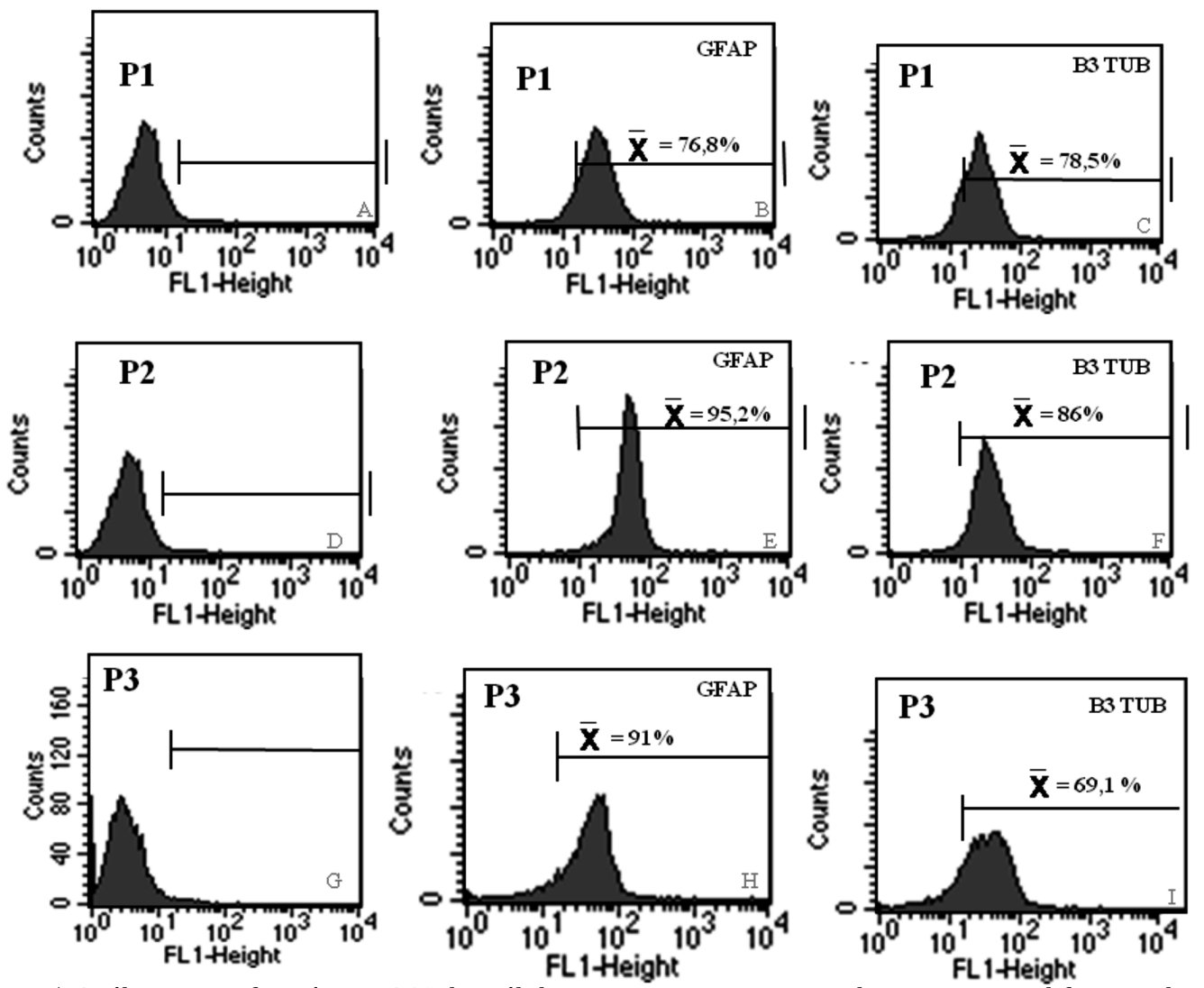

Fig.5. Análise imunofenotípica FACS das células-tronco mesenquimais de equino transdiferenciadas

(P1 e P2) e indiferenciadas (P3). a, b, c) Histogramas das células tratadas com forksolin e ácido retinóico (P1); a- controle, b- GFAP, c- $\beta 3$ tubulina. d, e, f) Histogramas das células tratadas com 2- $\beta$ mercaptoetanol (P2); d- controle, e- GFAP, f- $\beta 3$ tubulina. g, h, i) Histogramas das CTMs indiferenciadas, não submetidas a nenhum tratamento (Controle); g- controle, h- GFAP, i- $\beta 3$ tubulina. 
o marcador $\beta 3$ tubulina foi expresso em maior $(\mathrm{p}<0,001)$ proporção no P2 (86\%), seguido de P1 (78,5\%) e controle $(69,1 \%)$. Os histogramas referentes à análise fenotípica estão apresentados na Figura 5. É importante ressaltar, que de forma surpreendente as CTMs que não foram submetidas a nenhum tratamento também expressaram ambos os marcadores neurais (Fig.5).

\section{DISCUSSÃO}

O potencial das células tronco mesenquimais (CTMs) de transdiferenciar em certos tipos de células neurais tem despertado grande interesse, fomentando diversas pesquisas que visam o uso terapêutico deste tipo celular para o tratamento de diversas enfermidades de origem neurológica. Entretanto, dados claros e inequívocos em relação a esta transdiferenciação ainda precisam ser obtidos para fundamentar a validade de tais terapias.

No presente trabalho, as CTMs isoladas da medula óssea de equinos adultos foram adequadamente caracterizadas de acordo com os critérios estabelecidos pela Sociedade Internacional de Terapia Celular para CTMs humanas (Dominici et al. 2006), ou seja, apresentaram características de aderência ao plástico, morfologia fibroblastóide, elevada expressão do marcador CD90 ( $>95 \%$ positividade), negatividade de expressão ao marcador de células hematopoiéticas CD34 e responderam positivamente a diferenciação osteogênica. Duas ou mais dessas características também foram encontradas em outros estudos durante a caracterização de CTMs equinas provenientes do tecido adiposo (Carvalho et al. 2009, Carvalho et al. 2011), medula óssea (Arnhold et al. 2007, Guest et al. 2008, Radcliffe et al. 2010), sangue periférico (Martinello et al. 2010) e matriz do cordão umbilical (Hoynowski et al. 2007).

$\mathrm{Na}$ última década diversos tratamentos têm sido descritos visando a indução da diferenciação de CTMs em precursores neurais em diferentes espécies. Todos os protocolos utilizados até o momento podem ser divididos em três categorias básicas: 1) uso de agentes químicos; 2) uso de fatores de crescimento, e 3) cultivo de neuro-esfera, bem como a combinação entre estas categorias (Montzka et al. 2009). Neste experimento foram testados dois protocolos de indução química da diferenciação neural, sendo que no primeiro deles as células foram pré-tratadas com o fator de crescimento bFGF. Em ambos os protocolos observou-se mudança morfológica após o tratamento, sendo que esta ocorreu de forma mais abrupta no P2. Resultados semelhantes foram relatados por Woodbury et al. (2000) utilizando o mesmos agentes químico e por Mammadov et al . (2011) com ácido retinóico. Da mesma forma Hu et al. (2011) observaram alterações morfológicas usando Salvia miltiorrhiza e Nourbakhsh et al. (2011) utilizando fatores de crescimento.

Recentemente Mammadov et al. (2011) demonstraram que as CTMs submetidas a transdiferenciação neural com ácido retinóico modificam lentamente sua morfologia, enquanto que o uso de agentes químicos como o $\beta$-mercaptoetanol, o DMSO, e o KCl promovem uma rápida mudança atribuída a um artefato técnico devido ao enrugamento celular e não a aquisição da morfologia neuronal. Segundo estes autores, mudanças morfológicas mais lentas estão correlacionadas com a regulação de genes que requerem tempo para conversão em um tipo celular totalmente diferente, enquanto as mudanças rápidas parecem ser simplesmente decorrentes da ação tóxica dos compostos. Esta mesma opinião é compartilhada por Neuhuber et al. (2004) que observaram que as mudanças morfológicas para o fenótipo neural durante a transdiferenciação com uso de agentes químicos podem ser resultantes da quebra do citoesquelo e retração da borda celular. No presente trabalho a utilização do $\beta$-mercaptoetanol foi comparada a associação do acido retinóico com o forskolin. 0 forskolin é um agente ativador da adenilato ciclase e está relacionado aos níveis de adenosina monofosfato cíclica (cAMP), sendo considerado um dos melhores indutores da diferenciação neural para CTMs (Jori et al. 2005). Entretanto, de acordo com Zang et al. (2011) a mudança morfológica causada pelo AMPc nas CTMs também é ocasionada por alterações do citoesqueleto e enrrugamento celular, não sendo acompanhada por modificações da expressão gênica das células.

A estimativa da diferenciação neural tem sido fortemente baseada na morfologia das células, e na expressão de marcadores neurais (Deng et al. 2001, Jori et al. 2005). Apesar de ambos os protocolos utilizados no presente experimento, induzirem alterações na morfologia celular que estão associadas a modificações do citoesqueleto, indicando uma ação inespecífica, a expressão de marcadores neurais foi detectada com sucesso. A expressão dos marcadores gliais (GFAP) e/ou neurais ( $\beta 3$ tubulina) observadas na análise fenotípica após o tratamento $\operatorname{com} \beta$-mercaptoetanol (P2), bem como com ácido retinóico e forksolin (P1) também foram relatadas por Safford et al. (2004), Kingham et al. (2007), Bae et al. (2011), Ni et al. (2010) e Nourbakhsh et al. (2011) utilizando diferentes protocolos de "diferenciação neural". Neste experimento a análise imunofenotipica demonstrou maior expressão dos marcadores GFAP e $\beta 3$ tubulina no P2 comparativamente ao P1. Apesar disso a quantidade de células aderidas no P1, bem como a manutenção do "fenótipo neural" foi qualitativamente superior a observada no P2. Essa melhor aderência e integridade celular observadas em P1 podem ser decorrentes da menor toxidade do forksolin associado ao acido retinóico quando comparado ao $\beta$-mercaptoetanol.

Por outro lado, as CTMs que não foram submetidas a nenhum tratamento (controle) também expressaram ambos os marcadores neurais. Estudos utilizando diferentes técnicas (citometria de fluxo, imunocitoquímica, wester blot, PCR em tempo real) têm demonstrado que as CTMs provenientes de diferentes fontes não expostas ao meio de diferenciação neural expressam naturalmente alguns marcadores neurais como nestin, $\beta$ III tubulina, GFAP, tau e tirosina hidroxilase $(\mathrm{TH})$ em proporções variáveis (Safford et al. 2004, Kingham et al. 2007, Pelegrino 2009, Neuhuber et al. 2011). Adicionalmente tentativas prévias para identificar a expressão genética basal de CTMs revelaram a presença de genes característicos de células da linhagem endotelial, epitelial e neural, sendo que os RNAs relacionados a linhagem neural estão entre os 50 genes mais abundantes encontrados em outras linhagens celulares incluindo o marcador nestin (Montzka et al. 2009). 
É conhecido que CTMs que permanecem longo tempo em cultura (4 ou 5 passagens) podem sofrer diferenciação espontânea para linhagens semelhantes a neurais sem o estímulo de citocinas ou agentes químicos (Tseng et al. 2007). Além disso, neuroesteróides como a dexametasona e o estradiol são moduladores conhecidos de várias proteínas gliais induzindo a diferenciação de CTMs em células da linhagem neural que expressam nestin e a $\beta$ III tubulina (Bronzi et al. 2010). Embora, no presente estudo as CTMs utilizadas não tenham sido cultivadas por longos períodos, foi adicionado ao cultivo $20 \%$ de SFB, substância esta sabidamente rica em esteróides como os glicocorticóides e o estrógeno. Estes hormônios podem ter interagido com outros fatores de crescimento, também presentes no soro, desencadeando uma cascata de eventos em certa população de CTMs mais propensa a indução da diferenciação neural, o que resultou na expressão dos marcadores observada no grupo controle.

Entretanto, deve-se considerar que embora a presença destes marcadores moleculares seja um aspecto importante na caracterização da linhagem neural de células em cultivo, o principal aspecto a ser considerado ainda é a avaliação da funcionalidade das células transdiferenciadas através da mensuração do seu potencial de ação. Neste sentido, poucos são os trabalhos que comprovam a funcionalidade das células transdiferenciadas in vitro. Pelegrino (2009) estudando CTMs provenientes da polpa dentária humana observou, não só a expressão dos marcadores nestin e $\beta 3$ tubulina, mas também o disparo do potencial de ação nas células não submetidas a nenhum tratamento. Resultados como este ressaltam que a expressão natural de marcadores neurais em CTMs previamente a exposição aos "meios de diferenciação neural" e até mesmo a deflagração do potencial de ação, embora possam ocasionar dúvidas em relação a diferenciação para o fenótipo neural, são achados importantes por demonstrar a possibilidade de aplicação das CTMs em estado indiferenciado para diferentes enfermidades neurais.

A análise dos resultados do presente experimento demonstra que a habilidade das CTMs em gerar tipos celulares relacionados a linhagem neural é complexa e multifatorial, dependendo não só dos agentes indutores, mas também do ambiente no qual estas células são cultivadas. Além disso o presente experimento indica que a seleção celular baseada na aderência ao plástico, plasticidade e fenotipagem origina o desenvolvimento de uma população ainda heterogênea que responde de forma individual e imprevisível aos estímulos do meio de cultivo e fatores de indução de diferenciação. Desta forma um maior número de estudos é necessário para o melhor entendimento do processo de transdiferenciação neural a partir de CTMs de equinos.

Agradecimento.- À FAPESP pela concessão da bolsa de doutorado (Proc.2009/51431-6) e ao Fundunesp e CNPQ pelo auxilio financeiro.

\section{REFERÊNCIAS}

Arnhold S.J., Goletz I., Klein H., Stumpf G., Beluche L.A., Rohde C., Addicks K. \& Litzke L.E. 2007. Isolation and characterization of bone marrowderived equine mesenchymal stem cells. Am. J. Vet. Res. 68:1095-1105.

Bae K.S., Park J.B., Kim H.S., Kim D.S., Park D.J. \& Kang S.J. 2011. Neuron-
Like Differentiation of Bone Marrow-Derived Mesenchymal Stem Cells. Yonsei. Med. J. 52:401-412.

Barreira A.PB., Bacellar D.T.L., Kiffer R.G. \& Alves A.L.G. 2008. Punção aspirativa de medula óssea em eqüinos adultos paraobtenção de células-tronco. Revta Bras. Ciênc. Vet. 15:56-59.

Barzilay R., Kan I., Ben-zur T., Bulvik S., Melamed E. \& Offen D. 2008. Induction of Human Mesenchymal Stem Cells into Dopamine-Producing Cells with Different Differentiation Protocols. Stem Cells Dev. 17:547-554.

Bronzi D., Bramanti V., Tomassoni D., Laureanti F., Grasso S., Volsi G.L. \& Avola R. 2010. Neural markers espression in rat bone marrow mesenchymal stem cells treated with neurosteroids. Neurochem. Res. 35: 2154-2160.

Brooke G., Cook M., Blair C., Han R., Heazlewood C., Jones B., Kambouris M., Kolla K., McTaggart S., Pelekanos R., Rice A., Rossetti T. \& Atkinson K. 2007. Therapeutic applications of mesenchymal stromal cells. Semin. Cell. Dev. Biol. 18:846-858.

Carvalho A.M., Alves A.L.G., Golim M.A., Moroz A., Hussni C.A., Oliveira P.G.G. \& Deffune E. 2009. The isolation and immunophenotypic characterization of mesenchymal stem cells derived from equine species adipose tissue. Vet. Immunol. Immunopathol. 132:303-306.

Carvalho A.M., Alves A.L.G., Oliveira P.G.G., Alvarez L.E.C., Laufer-Amorim R., Hussni C.A. \& Deffune E. 2011. Use of adipose tissue-derived mesenchymal stem cells for experimental tendinitis therapy in equines. J. Equine Vet. Sci. 31:26-34.

Chen Y., Shao J.Z., Xiang L.X., Dong X.J. \& Zhang G.R. 2008. Mesenchymal stem cells: a promising candidate in regenerative medicine. Int. J. Biochem. Cell Biol. 40:815-820.

Dahlgren L.A. 2009. Stem Cell Therapy, p.908-911. In: Robinson N.E. \& Sprayberry K.A. (Eds), Current Therapy in Equine Medicine. $6^{\text {th }}$ ed. Saunders Elsevier, St Louis.

Deng W., Obrocka M., Fischer I. \& Prockop D.J. 2001. In vitro Differentiation of human marrow stromal cells into early progenitors of neural cells by conditions that increase intracellular cyclic AMP. Biochem. Biophys. Res. Commun. 282:148-152.

Dominici M., Le Blanc K., Mueller I., Slaper-Cortenbach I., Marini F.C., Krauses D.S., Deans R.J., Keatings A., Prockop D.J. \& Horowitz E.M. 2006. Minimal criteria for defining multipotent mesenchymal stromal cells: The International Society for Cellular Therapy position statement. Cytotherapy 8:315-317.

Frisbie D.D. \& Smith R.K.W. 2010. Clinical update on the use of mesenchymal stem cells in equine orthopaedics. Equine Vet. J. 42:86-89.

Guest D.J., Ousey J.C. \& Smith M.RW. 2008. Defining the expression of marker genes in equine mesenchymal stromal cells. Stem Cells and Cloning, Advances and Applications 1:1-9.

Hoynowski S.M., Fry M.M., Gardner B.M., Leming M.T., Tucker J.R., Black L., Sand T. \& Mitchell K.E. 2007. Characterization and differentiation of equine umbilical cord-derived matrix cells. Biochem. Biophys. Res. Commun. 362:347-353.

Hu L., Yu J., Li F., Chen B., LI L. \& Liu G. 2011. Effects of Salvia miltorrhiza in neural differentiation of rat mesenchymal stem cells with optimized protocol. J. Ethnopharmacol. 136:334-340

Jori F.P., Napolitano M.A., Melone M.A., Cipolaro M., Cascino A., Altucci L., Peluso G., Giordano A. \& Galderisi U. 2005. Molecular pathways involved in neural in vitro differentiation of marrow stromal stem cells. J. Cell Biochem. 94:645-655.

Kingham P.J., Kalbermatten D.F., Mahay D., Armstrong S.J., Wiberg M. \& Terenghi G. 2007. Adipose-derived stem cells differentiate into a Schwann cell phenotype and promote neurite outgrowth in vitro. Exp. Neurol. 207:267-274.

Lovati A., Corradeti B., Lange C.A., Recordati C., Bonacina E., Bizarro D. \& Cremonesi F. 2011. Comparison of equine bone marrow-umbilical cord matrix and amniotic fluid-derived progenitor cells. Vet. Res. Commun. 35:103-12.

Mammadov B., Karakas N. \& Isik S. 2011. Comparison of long-term retinoic acid-based neural induction methods of bone marrow human mesenchymal stem cells. In Vitro Cell Dev. Biol. Anim. 47:484-491. 
Martinello T., Bronzini I., Maccatrozoo L., Lacopetti I., Sampaolesi M., Mascarello F. \& Patruno M. 2010. Cryopreservation does not affect the stem characteristics of multipotent cells isolated from equine peripheral blood. Tissue Eng. C, Methods 16:771-781.

Montzka K., Lassonczyk N., Tschoke B., Neuss S., Fuhrmann T., Fransen R., Smeets R., Brook G.A. \& Woltje M. 2009. Neural differentiation potential of human bone marrow-derived mesenchymal stromal cells: misleading marker gene expression. BMC Neurosci. 10:1-12.

Naghdi M., Tiraihi T., Mesbah-Namin S.A. \& Arabkheradmand J. 2009. Induction of Bone Marrow Stromal Cells into Cholinergic-Like Cells by Nerve Growth Factor. Iran Biomed. J. 13:117-123.

Neuhuber B., Gallo G., Howard L., Kostura L., Mackay A. \& Fisher I. 2004. Reevaluation of In vitro differentiation protocols for bone marrow stromal cells: Disruption of actin cytoskeleton induces rapid morphological changes and mimics neuronal phenotype. J. Neurosci. Res. 77:192-204.

Ni W.F., Yin L.H., Lu J., Xu H.Z., Chi L.G., Wu J.B. \& Zhang Nu. 2010. In vitro neural differentiation of bone marrow stromal cells induced by cocultured olfactory ensheathing cells. Neurosci. Lett. 475:99-103.

Nourbakhsh N., Soleimani M., Taghipour Z., Karbalaie K., Seeidbehrouz M.S., Talebi A., Nadali F., Tanhaei S., Kiyani G., Nematollahi M., Rabiei F., Mardani M., Bahramiyan M., Torabinejad M., Nasr-Esfahani M.H. \& Baharvand $\mathrm{H}$. 2011. Induced in vitro differentiation of neural-like cells from human exfoliated deciduous teeth-derived stem cells. Int. J. Dev. Biol. 55:189-195

Pelegrino K.O. 2009. Caracterização e diferenciação neural in vitro de células-tronco de polpa dentária de dente decíduo humano. Dissertação de Mestrado em Biologia e Genética, Instituto de Biociências, Universidade de São Paulo, São Paulo, SP. 102p.

Pereira L.V. 2008. A importância do uso das células tronco para a saúde pública. Ciência e Saúde Coletiva 13:7-14.

Radccliffe C.H., Flaminio J.B.F., Fortier L. 2020. Temporal analysis of equine bone marrow aspirate during establishment of putative mesenchymal progenitor cell populations. Stem Cells and Dev. 19:269-281.

Safford K.M., Safford S.D., Gimble J.M., Shetty A.K. \& Rice H.E. 2004. Characterization of neuronal/glial differentiation of murine adipose-derived adult stromal cells. Exp. Neurol. 187:319-328.

Sanchez-Ramos J., Song S., Cardozo-Pelaez F., Hazzi C., Stedeford T., Willing A., Freeman T.B., Saporta S., Janssen W., Patel N., Cooper D.R. \& Sanberg P.R. 2000. Adult bone marrow stromal cells differentiate into neural cells in vitro. Exp. Neurol. 164:247-256.

Tseng P.Y., Chen C.J., Sheu C.C., Yu C.W. \& Huang Y.S. 2007. Spontaneous differentiation of adult rat marrow stromal cells in a long term culture. J. Vet. Med. Sci. 69:235-244.

Woodbury D., Schwarz E.J., Prockop D.J. \& Black L.B. 2000. Adult rat and human bone marrow stromal cells differentiate into neurons. J. Neurosci. Res. 61:364-370.

Ye Y., Zeng Y.M., Wan M.R. \& Lu X.F. 2011. Induction of human bone marrow mesenchymal stem cells differentiation into neural-like cells using cerebrospinal fluid. Cell Biochem. Biophys. 59:179-184.

Zhang L., Seitz L.C., Abramczyk A.M., Liu L. \& Chan C. 2011. CAMP initiates early phase neuron-like morphology changes and late phase neural differentiation in mesenchymal stem cells. Cell Mol. Life Sci. 68:863-876. 